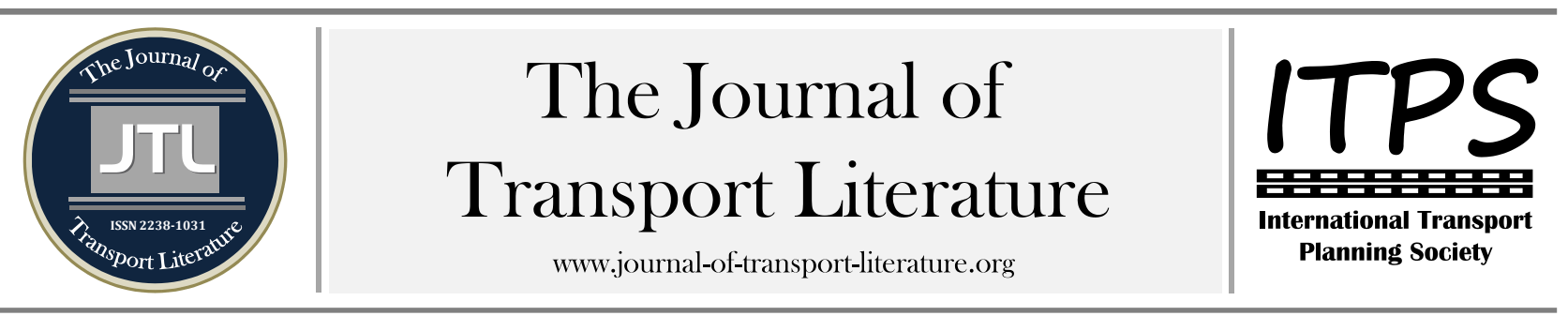

\title{
Comportamento e análise do ruído ferroviário na cidade de Santa Maria
}

Felipe Cipriani Luzzi; Tatiana Cureau Cervo+; Luciano Pivoto Specht

Universidade Federal de Santa Maria, Santa Maria, Rio Grande do Sul, Brasil

\section{Article Info}

Palavras-chave:

ferrovias

ruído

modeloestatístico

Submitted 9 Sep 2014;

received in revised form 29 Jan 2015

accepted 20 Apr 2015

Licensed under

Creative Commons

CC-BY 3.0 BR.

\section{Resumo}

0 trabalho teve por objetivo analisar o comportamento do ruído ferroviário na cidade de Santa Maria/RS, por meio da elaboração de uma expressão que demonstra a contribuição individual das variáveis estudadas (velocidade e distância). Foram utilizadas medições de campo e dados retirados de pesquisas semelhantes, objetivando maior confiabilidade nos resultados apresentados e possibilitando a ampliação da utilização do modelo proposto. Como no Brasil ainda não existem normas especificas para o estudo realizado, as regulamentações NBR 10151 e o Código de Posturas de Santa Maria foram utilizadas para o procedimento de coleta de dados e analise dos resultados. Os dados foram coletados na estação da GARE e na passagem de nível da Rua Sete de Setembro. Verificou-se que os valores obtidos estavam acima dos limites especificados pelas normativas existentes, sendo 72,88 dB e 83,42 dB o menor e o maior encontrados, respectivamente. Os resultados encontrados a partir dos estudos foram analisados em conjunto com os dados de Spechtet al. (2012), montando-se curvas de ruídos que se mostraram relevantes e confiáveis para velocidades de 0 a $25 \mathrm{~km} / \mathrm{h}$ e distâncias do receptor de 0 a $20 \mathrm{~m}$.

+ Correspondingauthor. Universidade Federal de Santa Maria- CT- Depto. De Transportes - Campus Universitário - Camobi - CEP 97105-900 - Santa Maria - RS E-mail address: cervo.tatiana@ufsm.br

\section{Introdução}

Este trabalho teve por objetivo elaborar um modelo de previsão de ruído, a partir de ensaios de campo, caracterizando o comportamento do ruído ferroviário da cidade de Santa Maria, a fim de serem instituídas medidas para maior conforto populacional, além do uso deste método em regiões que apresentem características semelhantes.

0 transporte ferroviário tem grande impacto quando o assunto é poluição sonora a qual pode ser chamada de contaminação atmosférica. 0 ruído causado pelos trens, de maneira geral, é um grande responsável pelo desconforto populacional e pelas doenças relacionadas a problemas auditivos dos trabalhadores dos comboios ferroviários.

Os efeitos nocivos podem se expandir e, economicamente, podem afetar a população vizinha, visto que pode haver desvalorização imobiliária no entorno da via. Analisar o ruído dos trens e montar métodos para que se possa conhecer o comportamento do ruído em regiões diferentes é um meio eficaz de proteger as pessoas.

A pesquisa se propôs a determinar curvas de previsão de ruído, tomando por variáveis a velocidade do comboio e a distância do receptor. Foi possível verificar se os níveis de ruídos encontrados se enquadravam nos limites estipulados para região urbana, permitidos pelo município.

Uma comparação com os estudos de Spechtet al. (2012) na cidade de Ijuí/RS foi realizada, o que possibilitou ampliar o conhecimento de níveis de ruídos para uma maior quantidade de distâncias e velocidades.

No capitulo que segue, uma breve revisão da bibliografia explanará os principais assuntos referentes ao ruído no modal ferroviário, seus efeitos e suas formas de controle, bem como os principais métodos utilizados para previsão de ruído na ferrovia. Na sequência, apresenta-se a metodologia aplicada, análise dos resultados obtidos e por fim, as conclusões a partir de resultados e comparações realizadas com parâmetros existentes.

\section{Métodos de Previsão de Ruído Ferroviário}

Segundo Barreto (2007) os métodos de previsão têm que atender a dois objetivos principais: prever valores de ruídos associados a um único trem, desconsiderando ruído de fundo e permitir que estes valores possam ser usados em estudos ambientais, usando como referência ruídos em Leq.

O Ministério da Habitação, Urbanismo e Meio Ambiente juntamente com a Empresa Brasileira de Transportes Urbanos (MHU, 1988) preconiza a aplicação dos seguintes métodos de previsão de ruído de tráfego ferroviário para o Brasil.

a. Método de R. Lotz (método norte americano)

b. Método Francês (SNCF, RATP, CSTB)

O Primeiro método usa a Equação (1):

$$
L_{A}^{\prime}=L_{A}+10 \log \left[\frac{d \cdot \frac{l^{\prime}}{2 d^{\prime}}}{d^{\prime} \cdot \frac{l}{2 d}}\right]
$$


Sendo: L’A -nível de pressão sonora equivalente; ı - comprimento da composição do trem, em m; d - distância entre o observador e o centro da linha, em m; l' - valor normatizado do comprimento do trem (nos EUA - 23m); d' - valor normatizado da distância entre o observador e o centro da linha (nos EUA - 15m).

0 método francês utiliza a Equação (2) para previsão de ruído de trafego ferroviário.

$$
L_{\text {max }}=L_{0}-K \log \frac{d}{d_{0}}+30 \log \frac{V}{V_{0}}-K_{d}
$$

Sendo: Lmáx- nível máximo de pressão sonora $\mathrm{dB}(\mathrm{A})$; Lo - nível sonoro de referência emitido por um trem de determinado tipo, circulando a velocidade Vo , percebido por um observador situado a uma distância do , a uma altura normatizada ho, em $\mathrm{dB}(\mathrm{A}) ; \mathrm{k}$ = coeficiente multiplicador da função distância, dependente do comprimento do trem; $\mathrm{d}=$ distância entre o observador e o eixo da via férrea, em $\mathrm{m}$; do = distância de referência onde o trem emite o nível Lo, em $\mathrm{m}$; $\mathrm{V}$ = velocidade do trem, em $\mathrm{km} / \mathrm{h} ; \mathrm{Vo}=$ velocidade do trem que emite um nível Lo, a uma distância do, em $\mathrm{km} / \mathrm{h}$; $\mathrm{kd}=$ corretivo de direção

Este segundo método muitas vezes não é utilizado como referência, pois ele apenas encontra o valor máximo do nível de pressão sonora e, não o equivalente.

\section{Metodologia}

Na busca e interpretação dos dados e na inexistência de normas especificas para o estudo, o método utilizado foi encontrado na NBR 10151, o qual é dito como medição do nível de pressão sonora equivalente em resposta rápida A (LAeq). Essa mesma norma foi também utilizada por Carvalho et. al (2014) para prever curvas de ruído em aeroportos empregando LAeq. Para a realização das medições usou-se as condições gerais para medições no exterior de edificações: distância mínima de 2,0 m do ponto de emissão e 1,2 m de altura do nível de referência.

A recomendação da NBR 10151 é que o decibelímetro possua recursos para medição de nível de pressão sonora equivalente ponderado em "A" (LAeq). 0 medidor de pressão sonora utilizado na coleta não possuía este recurso e a NBR 10151 prevê nestes casos o uso de uma expressão presente em seu Anexo "A" (Equação (3)).

$$
L_{\text {Aeq }}=10 \log \frac{1}{n} \sum_{i=1}^{n} 10^{\frac{l i}{10}}
$$

Sendo: LAeq- nível de pressão sonora equivalente em resposta rápida; li - o nível de pressão sonora, em $\mathrm{dB}(\mathrm{A})$, lido em resposta rápida (fast) a cada 5 segundos, durante pelo menos cinco minutos; $n$ o número total de leituras.

Os locais escolhidos para a pesquisa foram a antiga estação da GARE (próximo a Av. Rio Branco) e a passagem de nível do cruzamento da linha férrea com a Rua 7 de setembro, ambos na cidade de Santa Maria no Rio Grande do Sul. A coleta de dados e a análise foram desenvolvidas a partir da distância do receptor ao eixo da via e da velocidade dos comboios, razões estas as mais relevantes quando calculados os resultados.

As medições foram realizadas nas distâncias de 7,5, 10 e 15 metros, nos dois pontos analisados, em relação ao eixo da via, assim como foi medido o nível de pressão sonora do ambiente, ou seja, sem a passagem de trens. Estas medidas foram escolhidas, pois segundo Vendramini (2009) para trens convencionais, a decisão da comissão 2006/66/EC pontua níveis de pressão sonora para ruído estacionário e em movimento, medidos a 7,5 m da linha de centro dos trilhos, a 1,2 m de altura.

A velocidade das composições foi medida a partir de um processo simples, conhecendo-se o comprimento dos trens e o tempo de passagem entre a locomotiva e o vagão cauda, com o auxilio de um cronômetro. Os valores encontrados estavam dentro do intervalo de 9 a $15 \mathrm{Km} / \mathrm{h}$, sendo estas relativamente baixas, por estarem em um trecho de pátio.

Para o processo de coleta dos dados em campo, foi utilizado um medidor de pressão sonora com leitor digital de quatro dígitos, modelo TM-101 - POL - 09 da Politerm assente sobre um tripé.

\section{Resultados}

\subsection{Análises do comportamento de passagem e comparação com a normativa existente}

Para melhor compreensão, a tabela 1 resume os dados obtidos em todas as medições realizadas, apresentando os valores obtidos de ruído pela passagem de trem e a média dos valores (a partir de uma amostra de doze medidas) de ruído ambiente. Vale salientar que estes valores não estão considerando a buzina do trem.

\begin{tabular}{ccc}
\multicolumn{3}{c}{ Tabela 1 - Resumo dos dados de Leq $(\mathrm{A})$ coletados em campo } \\
\hline Distância $(\mathrm{m})$ & Velocidade $(\mathrm{km} / \mathrm{h})$ & Ruído $(\mathrm{dB}(\mathrm{A}))$ \\
7,5 & 13,35 & 83,42 \\
7,5 & 10,08 & 80,81 \\
10 & 9,43 & 76,97 \\
10 & 9,22 & 75,86 \\
15 & 14,1 & 74,76 \\
15 & 9,47 & 72,88 \\
Ruído ambiente $=65,14 \mathrm{~dB}(\mathrm{~A})$ & \\
\hline
\end{tabular}

Pelo código de posturas para a cidade de Santa Maria (tabela 2) a área considerada é residencial/comercial e vê-se que os valores de ruído encontrados estão bem acima dos regulamentados e fora dos padrões seguros para a saúde humana. 0 ruído ambiente também é maior que o especificado em norma, o qual é o maior problema, por ser uma medida constante.

Uma análise complementar pode ser realizada a partir da tabela de Vendramini (2006), a qual descreve o valor de ruído para trens convencionais a altas velocidades ( $80 \mathrm{~km} / \mathrm{h})$, medidas a 7,5 $\mathrm{m}$ da linha de centro dos trilhos, a 1,2 $\mathrm{m}$ de altura. A Tabela 3 ilustra estes limites.

Nota-se que para trens convencionais a diesel com múltiplos vagões, o ruído máximo em andamento é de $82 \mathrm{~dB}$. Os dados obtidos, a 7,5m, em Santa Maria, são de $83,42 \mathrm{~dB}$ a $13,35 \mathrm{~km} / \mathrm{h}$ e $80,81 \mathrm{~dB}$ a $10,08 \mathrm{~km} / \mathrm{h}$, o que mostra que a situação do ruído gerado pelos trens santa-marienses pode ser preocupante. 
Tabela 2 - Ruído para diferentes zonas de Santa Maria, em dB (A)

$$
\text { Zonas de Uso }
$$

Diurno Vespertino Noturno

Zona Residencial (estritamente); Zona Agrícola; Centro Cívico

$55 \quad 50 \quad 45$

Zona Residencial/Comercial

Zona Residencial/Industrial; Zona Comercial/Industrial

60

65

Zona Industrial (estritamente)

Fonte: adaptado de Código de posturas para ambientes externos de Santa Maria/RS

Tabela 3 - Limites de ruído para trens europeus convencionais, em dB(A)

Tipo de Veículo Ruído parado

Ruído andamento

Locomotivas elétricas

Locomotivas a diesel

$75 \quad 85$

Trens elétricos c/ múltiplos vagões

75

Trens a diesel c/ múltiplos vagões

68

85

Vagões de passageiros

\subsection{Elaboração da expressão para previsão do ruído}

A equação desenvolvida tem duas variáveis independentes (velocidade e distância) e o ruído, variável dependente. Foi necessário criar uma relação entre as diferentes variáveis, de tal forma que cada uma contribua para o resultado final. A ideia central foi fazer um processo de regressão nos dados e, buscando-se uma equação final do tipo (Equação (4)):

$$
y=a_{1} \cdot x_{1}+a_{2} \cdot x_{2}+a_{3}+\varepsilon
$$

Sendo: a1, a2 e a3 os coeficientes provenientes da regressão linear; x1 e x2 as variáveis independentes velocidade e distância; y a variável dependente ruído; e $\varepsilon$ o erro atribuído a discrepância dos dados observados com os dados obtidos no método.

Além das variáveis estudadas, alguns outros fatores podem contribuir para o ruído medido, todavia em menor grau de importância, como a temperatura e umidade do ar e o ruído de fundo, este último, muito dependente do local da avaliação.

Como o comportamento do ruído é logarítmico, não se pode regredir linearmente. A solução adotada, de maneira simples e eficaz, foi extrair o logarítmico dos valores de ruído. A Tabela 4 mostra o resultado da extração do logaritmo dos dados.

Tabela 4 - Logaritmo dos valores de Ruído

\begin{tabular}{cccc}
\hline Distância $(\mathrm{m})$ & Velocidade $(\mathrm{km} / \mathrm{h})$ & Ruído $(\mathrm{dB}(\mathrm{A}))$ & Log Ruído $(\mathrm{dB}(\mathrm{A}))$ \\
7,5 & 13,35 & 83,42 & 1,9213 \\
7,5 & 10,08 & 80,81 & 1,9075 \\
10 & 9,43 & 76,97 & 1,8863 \\
10 & 9,22 & 75,86 & 1,8800 \\
15 & 14,1 & 74,76 & 1,8737 \\
15 & 9,47 & 72,88 & 1,8626 \\
Ruído ambiente $=65,14 \mathrm{~dB}(\mathrm{~A})$ & & \\
\hline
\end{tabular}

Fonte: os autores

Com esta "linearização", a regressão linear pôde ser realizada usando valores do logaritmo do ruído, distância e velocidade. Com a regressão linear e a partir do uso do método dos mínimos quadrados os coeficientes puderam ser encontrados e estão ilustrados na tabela 5.

Tabela 5 - Coeficientes da equação

\begin{tabular}{lc}
\hline Coeficientes & Valores \\
Velocidade (a1) & 0,00415 \\
Distância (a2) & $-0,00604$ \\
Interseção (a3) & 1,90856 \\
\hline
\end{tabular}

\section{Fonte: os autores}

Encontrados os coeficientes, a equação resultante ficou do tipo (Equação (5)):

$$
\log _{\text {ruído }}=0,00415 . \text { Vel }-0,00604 \text {. Dist }+1,90856
$$

Fazendo-se o cálculo do logaritmo, tem-se (Equação (6)):

$$
R=10^{(0,00415 . V e l-0,00604 . D i s t+1,90856)}(6)
$$

Sendo: Vel: velocidade em Km/h; Dist: Distância do receptor ao eixo da via em metros; R: ruído em dBA

A equação obteve como resultado estatístico, um $\mathrm{R}^{2}$ de 0,96 indicando $96 \%$ de confiabilidade. Para análise dos erros embutidos dentro da equação, os valores encontrados a partir desta foram comparados com os medidos em campo, com as mesmas distâncias e velocidades. 0 resumo dos valores encontra-se na tabela 6.

É possível observar que os valores obtidos em campo são muito próximos àqueles resultantes da equação, indicando que a equação pode ser utilizada quando se trata de valores de comportamento de ruído e não valores absolutos.

A partir da expressão elaborada montou-se o gráfico da figura 6 com os valores de ruído determinados a partir da velocidade, onde cada curva representa uma distância em relação ao eixo da via. 
Tabela 6 - Diferenças entre valores medidos em campo e calculados com a equação do método proposto

\begin{tabular}{lcccc}
\hline $\begin{array}{c}\text { Velocidade } \\
(\mathrm{km} / \mathrm{h})\end{array}$ & $\begin{array}{c}\text { Distância } \\
(\mathrm{m})\end{array}$ & $\begin{array}{c}\text { Ruído }(\mathrm{dB}(\mathrm{A})) \\
\text { obtido equação }\end{array}$ & $\begin{array}{c}\text { Ruído(dB(A)) } \\
\text { medido em campo }\end{array}$ & $\begin{array}{l}\text { Diferença } \\
(\mathrm{dB}(\mathrm{A}))\end{array}$ \\
13,35 & 7,5 & 82,9206 & 83,4200 & $-0,4994$ \\
10,08 & 7,5 & 80,3696 & 80,8100 & $-0,4404$ \\
9,43 & 10 & 77,1426 & 76,9700 & 0,1726 \\
9,22 & 10 & 76,9880 & 75,8600 & 1,1280 \\
14,1 & 15 & 75,2445 & 74,7600 & 0,4845 \\
9,47 & 15 & 71,9881 & 72,8800 & $-0,8919$ \\
\hline
\end{tabular}

\subsection{Elaboração da expressão para previsão de ruído em ambientes urbanos}

Com o intuito de expandir a equação desenvolvida para o ruído ferroviário foram empregados os dados de Spechtet al. (2012) resultantes de estudo e características ferroviárias semelhantes realizados na cidade de Ijuí/RS.

A Tabela 7 resume os dados utilizados para a construção da nova equação. Nota-se que os valores encontrados por Spechtet al. (2012), têm maiores velocidades e, também maiores distâncias.

Com utilização da regressão linear, a equação para previsão de ruídos urbanos obtida foi a Equação (7), com $\mathrm{R}^{2}$ de 0,78 : $R=10^{(0,00705 . V e l-0,00094 . \text { Dist }+1,82584)}$

Sendo: Vel: velocidade em km/h; Dist: Distância do receptor ao eixo da via em metros; R: ruído em dB(A)

Da mesma maneira do item anterior, para avaliação dos erros embutidos no método, os dados medidos em campo foram comparados com os obtidos após o uso da equação. Estes resultados estão ilustrados na tabela 8.

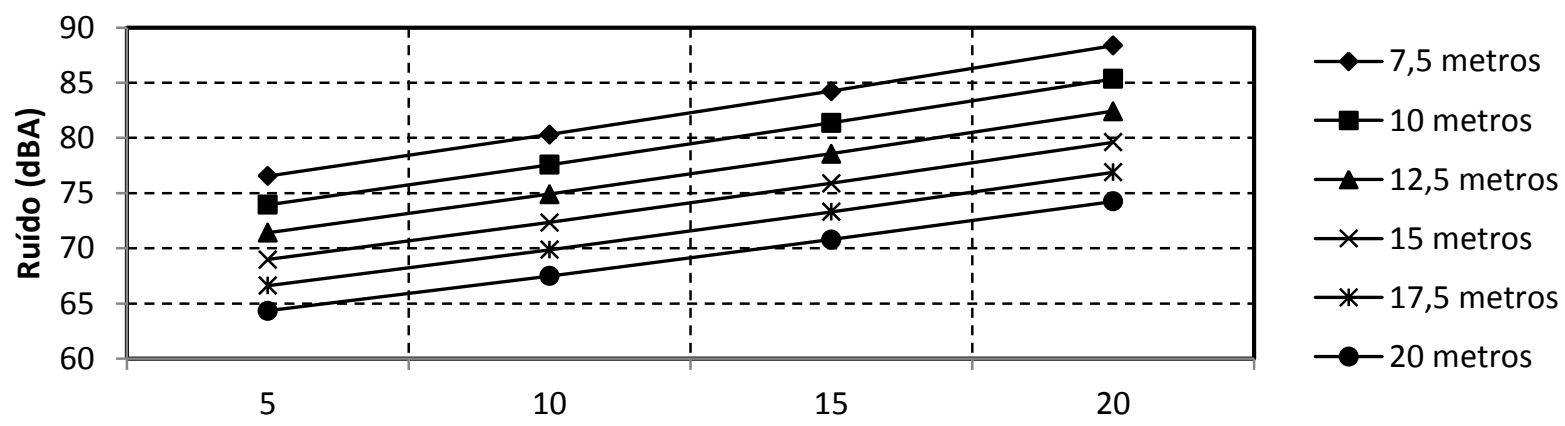

Velocidade $(\mathrm{km} / \mathrm{h})$

Figura 6 - Ábaco de Ruído em função de velocidade e distância

Tabela 7 - Resumo dos dados obtidos em campo e retirados da bibliografia

\begin{tabular}{cccc}
\hline Distância (m) & Velocidade $(\mathrm{km} / \mathrm{h})$ & Ruído $(\mathrm{dB}(\mathrm{A}))$ & Log ruído $(\mathrm{dB}(\mathrm{A}))$ \\
7,5 & 10,08 & 80,81 & 1,9075 \\
7,5 & 13,35 & 83,42 & 1,9213 \\
10 & 9,22 & 75,86 & 1,8800 \\
10 & 9,43 & 76,97 & 1,8863 \\
15 & 9,47 & 72,88 & 1,8626 \\
15 & 14,1 & 74,76 & 1,8737 \\
15 & 19,04 & 92,79 & 1,9675 \\
15 & 23,25 & 93,73 & 1,9719 \\
30 & 19,04 & 88,8 & 1,9484 \\
30 & 23,25 & 88,69 & 1,9479 \\
45 & 19,04 & 85,71 & 1,9330 \\
45 & 23,25 & 86,65 & 1,9378 \\
\hline
\end{tabular}

Também foi montado um gráfico para facilitar o encontro de valores de ruído a partir da velocidade e da distância (figura 7). Este ábaco melhora a percepção de quem quer buscar valores de ruídos, conhecendo-se a distância do receptor e também a velocidade do comboio. Cada curva representa uma velocidade. A extrapolação do gráfico é válida já que se busca um comportamento do ruído ferroviário e não valores absolutos. Pode-se dizer que esta equação pode resultar em valores aproximados e ser introdutório a novos trabalhos que vierem a ser realizados.

A figura 8 compara os valores de resultados previstos versus analisado, e verifica-se que a distribuição é harmônica em torno da linha de igualdade, mostrando que para a faixa de valores medidos (entre 70 e $95 \mathrm{~dB}(\mathrm{~A})$ ), o modelo proposto é consistente. 


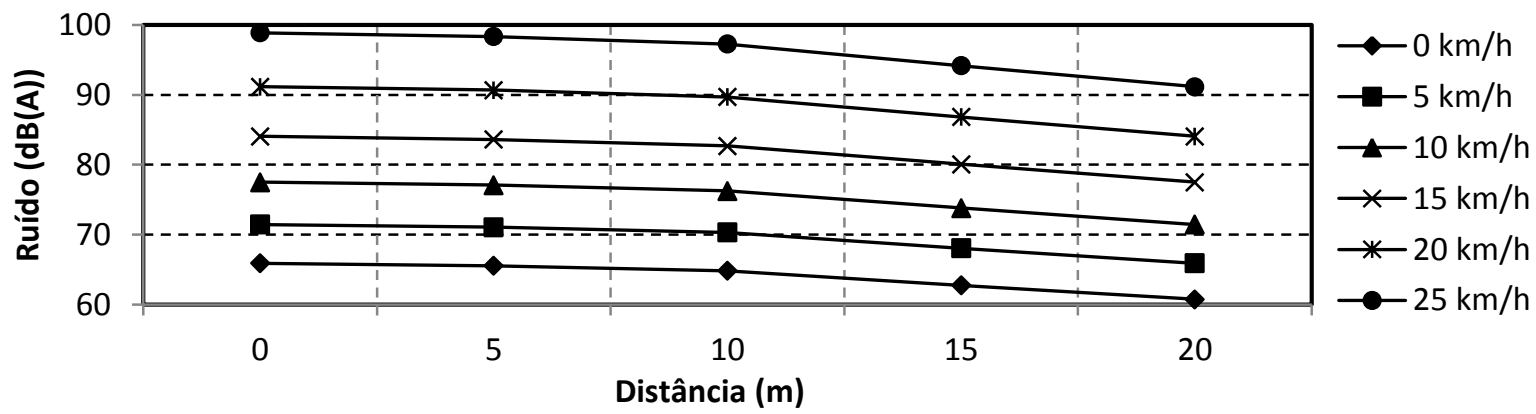

Figura 7 - Previsão de Ruído de trafego ferroviário urbano

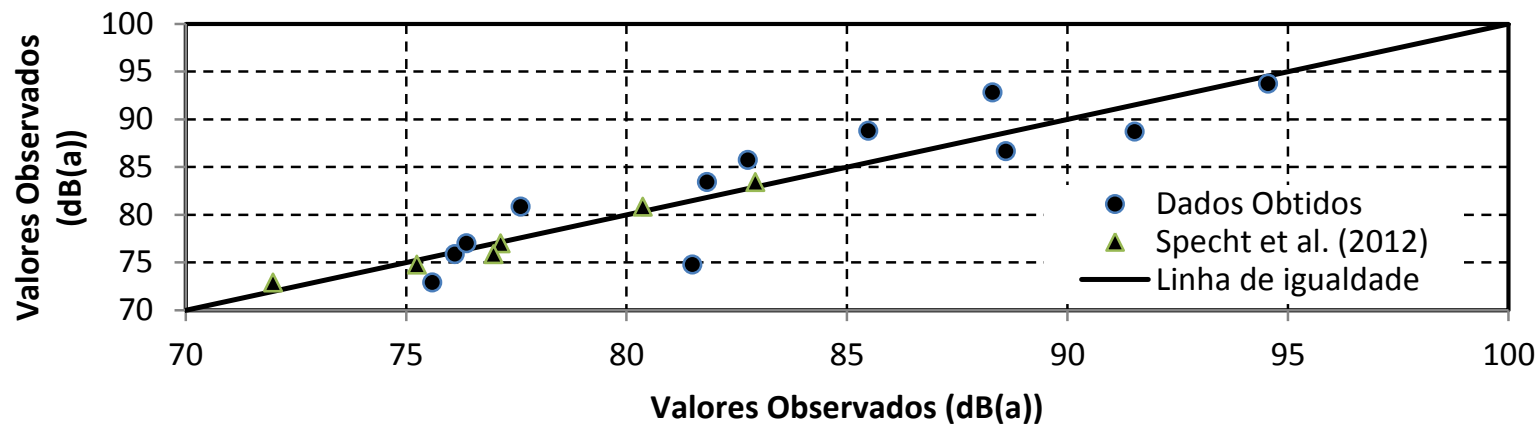

Figura 8 - Valores previstos versus valores analisados

\section{Conclusões}

O presente trabalho teve por objetivos, analisar o comportamento do ruído causado pelo transporte ferroviário na cidade de Santa Maria, elaborando uma expressão que estime o ruído na cidade e em ambientes com características semelhantes.

0 método do anexo "A" da NBR 10151 foi utilizado para a coleta de dados. Nos dois pontos de coleta, as distâncias de 7,5, 10 e 15 metros foram utilizadas para montar uma faixa de comportamento do ruído em questão.

Os valores obtidos nas medições ficaram limitados entre 70 e $85 \mathrm{~dB}$ para o ruído e, entre 9 e $15 \mathrm{~km} / \mathrm{h}$, para velocidade, quando das medições com o trem em movimento. 0 ruído médio de ambiente encontrado foi de $65,14 \mathrm{~dB}$. Comparando estes valores aos limites do Código de Posturas de Santa Maria, nota-se que os valores estão acima dos previstos por estas regulamentações. Deve-se, a partir do mencionado, alertar-se que soluções atenuadoras devem ser adotadas para a minimir dos defeitos nocivos causados pelo ruído.

Por fim, destaca-se que os resultados obtidos permitiram modelar estatisticamente o comportamento do ruído ferroviário e, mesmo com as restrições (erros embutidos e base de dados restrita a dois locais), são bastante eficazes para estimar o ruído subsidiando futuros projetos no âmbito da engenharia ferroviária.

0 modelo ganha envergadura também, visto que no Brasil ainda não existem métodos específicos para a realização de levantamentos de dados e normativas que indiquem os níveis aceitáveis para ruído ferroviário, bem como modelos de previsão.

\section{Referências}

Associação Brasileira de Normas Técnicas (2000). Acústica - avaliação do ruído em áreas habitadas, visando o conforto da comunidade procedimentos: NBR 10151.

Barreto, D. M (2007). Impacto Sonoro da Implantação do Metrô de Salvador em Edificações Adjacentes Considerando os Efeitos na População. Dissertação de mestrado, UFBA.

Carvalho, L. A., Slama, J. G., Nassi, C. D. (2014). A complementary metric to define a buffer zone in brazilian airports. JournalofTransportLiterature, n. 4, vol8, p.4-12.

Código de Posturas do Município de Santa Maria (CPSM) (2002). Lei Complementar № 003/02 de 22/01/2002. Dispõe sobre o código posturas do município de Santa Maria e dá outras providências.

Ministério da Habitação e Meio Ambiente; Ebtu-Empresa Brasileira dos Transportes Urbanos (1998). Manual Operacional de Avaliação dos Impactos Ambientais de Projetos de Transportes Urbanos.

Specht, L. P. ; Kohler, R. ; Bronzatti, G.(2012) . Ruído causado pelo transporte ferroviário em um segmento urbano: estudo do caso da cidade de Ijuí-RS. Teoria e Prática na Engenharia Civil (Online), v. 19, p. 13-23.

Vendramini, C.E e Paul, S. Ruído Ferroviário (2009). Revista da Sociedade Brasileira de Acústica, n. 40, p.55-63.

\section{Abstract}

The work aimed to analyze the noise behavior in the railways in the city of Santa Maria/RS, through the development of an expression that shows the individual contribution of the variables studied. Is possible to note that field measurements and data from similar researches were used, aiming to increase reliability in the results and enabling the expansion of the use of the proposed model. As in Brazil there aren't specific standards for the study, the NBR 10151 normative and the Code of Postures of Santa Maria were used for the data collection procedure and analysis of results. Data were collected at the station GARE and level crossing RuaSete de Setembro. Among the values it was noted that all were above the limits specified by existing regulations, $72.88 \mathrm{~dB}$ and $83.42 \mathrm{~dB}$ the lowest and the highest found, respectively. The results from the studies were analyzed together with the data from Specht et al. (2012), setting up noise curves that were relevant and reliable for train speeds from 0 to $25 \mathrm{~km} / \mathrm{h} 0$ receptor distances $20 \mathrm{~m}$.

Key words: railways, noise, statistic modeling. 